\title{
Plural Marking in Spoken and Written Narratives: A Corpus-based Study of Japanese Learners of English
}

\author{
Yumiko Yamaguchi (Corresponding author) \\ International Education Center, Tokai University, 4-1-1, Kitakaname, Hiratsuka-shi, Kanagawa, 259-1292 Japan \\ E-mail: yyamaguchi@tokai-u.jp \\ Hiroko Usami \\ International Education Center, Tokai University, 4-1-1, Kitakaname, Hiratsuka-shi, Kanagawa, 259-1292 Japan \\ E-mail: hiroko.usami@tokai-u.jp
}

Received: 17-03-2017

Published: 01-09-2017
Accepted: 11-05-2017

doi:10.7575/aiac.ijalel.v.6n.5p.224
Advance Access Published: July 2017

URL: http://dx.doi.org/10.7575/aiac.ijalel.v.6n.5p.224

\begin{abstract}
This paper aims to present the results of a learner corpus study on spoken and written narratives by Japanese learners of English using Processability Theory (PT) (Pienemann, 1998). PT assumes that there is a universal hierarchy of second language (L2) development and many studies (e.g., Di Biase, Kawaguchi, \& Yamaguchi, 2015; Pienemann, 1998) have shown support for PT stages for English L2. However, few PT studies have addressed the issues of whether learners use linguistic structures in the same way in spoken and written tasks. The current study focuses on learners' use of plural marking on nouns, since contradictory results have been reported for the developmental sequence of lexical plural $-s$ and phrasal plural $-s$ (Charters, Dao, \& Jansen, 2011). The participants in this study comprised 291 university students learning in English programs in Japanese universities. Each of them performed spoken and written narratives using a picture book titled Frog, where are you? (Mayer, 1969) containing 24 wordless pictures. The learner corpus including both 291 audio-recorded and transcribed spoken narratives and 291 written narratives was compiled. The results of the analyses showed a connection between learners' use of plural marker $-s$ in speaking and that in writing, while a small number of students were found to perform differently in two different tasks. Moreover, this study demonstrated support for the developmental sequence of lexical and phrasal plural marking predicted in PT.
\end{abstract}

Keywords: English plural marking, learner corpus, Processability Theory, speaking, writing, narratives

\section{Introduction}

The aim of this study is to investigate the use of English grammatical structures by Japanese learners in speaking and writing within the framework of Processability Theory (PT) (Pienemann, 1998). PT has been tested in various language contexts, including second language (L2), foreign language (FL), and bilingual first language contexts and the developmental stages of English syntax and morphology predicted in PT have been supported by many studies (e.g., Di Biase, Kawaguchi, \& Yamaguchi, 2015; Pienemann, 1998). However, there are some areas that require further investigation in order to improve the processability hierarchy for English. One of the issues for English PT stages is the development of the plural morpheme $-s$ according to its linguistic context (i.e., without quantifiers, with numeric or non-numeric quantifiers). In many PT studies based on longitudinal data (e.g., Di Biase, Kawaguchi, \& Yamaguchi, 2015; Yamaguchi, 2009, 2013; Yamaguchi \& Kawaguchi, 2015) the plural morpheme $-s$ without quantifiers was acquired before that with quantifiers; however, a cross-sectional study (Charters, Dao, \& Jansen, 2011) obtained contradictory results showing a case where plural marking with numeric quantifiers developed earlier than that without quantifiers. Additionally, since most PT studies have been conducted utilizing spoken tasks, such as structured interviews, picture descriptions, and communicative tasks, research which compared the learners' PT stages in speaking with those in writing (e.g., Tang \& Zhang, 2015; Yamaguchi \& Usami, 2016) are very rare. Furthermore, PT stages have never been tested based on large-scale corpora. Therefore, the current study attempts to clarify and contribute to our understanding of the hypothesized PT stages based on both spoken and written data from a large number of language learners. In order to achieve this aim, we constructed a learner corpus of spoken and written narratives by Japanese learners of English in foreign language environments, and we investigated these learners' use of English morphological structures, particularly their use of the plural morpheme $-s$ in both spoken and written tasks.

\section{Background}

\subsection{Processability Theory}

In this study, Processability Theory (PT) (Pienemann, 1998) is used as a theoretical framework to analyze the developmental stages of English by focusing on plural marking in the learners' speaking and writing. PT is a theory of second language acquisition based on the architecture of human language processing and claims that there is a universal 
hierarchy of processing resources that can be related to language-specific processing requirements. In PT, L2 developmental stages of grammatical structures are hypothesized based on Levelt's Speech Model and Lexical Functional Grammar. PT predicts a processability hierarchy as follows: Lemma access $>$ category procedure $>$ phrasal procedure $>$ sentence procedure $>$ subordinate procedure (if applicable).

PT assumes that each lower level is a prerequisite for the functioning of the higher level. The English morphological structures predicted to emerge at each PT stage using Lexical Functional Grammar (e.g., Bresnan, 2001) are summarized in Table 1. According to the table, learners are able to use only invariant forms at stage 1 and become able to supply lexical morphemes, such as plural $-s$ on nouns without quantifiers, -ing on verbs without auxiliaries, and past $e d$ on verbs at stage 2 , where the category procedure develops in the learner language. Then, at stage 3 , where phrasal procedure develops, information exchange between two constituents within the phrase become possible, and learners start supplying noun phrase (NP) morphology, that is, the phrasal plural $-s$ on nouns with quantifiers, as in many dogs. It is also predicted that morphemes can be supplied on verbs in accordance with the auxiliaries at stage 3. At stage 4, where sentence procedure develops, third person singular $-s$ on verbs, as in Peter loves rice, can be produced since learners become able to exchange the information between two phrases (i.e., the noun phrase and the verb phrase).

Table 1. PT stages for English L2 morphology (After Pienemann, 1998, 2005)

\begin{tabular}{|c|c|c|c|}
\hline Stage / Procedure & $\begin{array}{l}\text { Morphological } \\
\text { outcome }\end{array}$ & Structure & Example \\
\hline $\begin{array}{l}\text { 4. Sentence } \\
\text { procedure }\end{array}$ & $\begin{array}{l}\text { Interphrasal } \\
\text { morphology }\end{array}$ & 3rd person singular $-s$ & Peter loves rice \\
\hline \multirow{2}{*}{$\begin{array}{l}\text { 3. Phrasal } \\
\text { procedure }\end{array}$} & VP morphology & $\begin{array}{l}\text { AUX }+\mathrm{V}: \\
\text { have }+\mathrm{V} \text {-ed } \\
\text { MODAL }+\mathrm{V} \\
\text { be }+\mathrm{V} \text {-ing }\end{array}$ & $\begin{array}{l}\text { they have walked } \\
\text { you can go } \\
\text { I am going }\end{array}$ \\
\hline & NP morphology & $\begin{array}{l}\text { phrasal plural -s } \\
\text { (with quantifiers) }\end{array}$ & $\begin{array}{l}\text { these girls } \\
\text { many dogs } \\
\text { three cats }\end{array}$ \\
\hline $\begin{array}{l}\text { 2. Category } \\
\text { procedure }\end{array}$ & Lexical morphology & $\begin{array}{l}\text { past -ed } \\
\text { verb -ing (without AUX) } \\
\text { plural - } s \text { (without quantifiers) }\end{array}$ & $\begin{array}{l}\text { Mary jumped } \\
\text { he working } \\
\text { I miss my friends }\end{array}$ \\
\hline 1. Lemma access & Invarian forms & Invariant forms & dog, girl \\
\hline
\end{tabular}

\subsection{Previous studies}

PT stages of English morphology have been tested in many studies (e.g., Charters, Dao, \& Jansen, 2011; Di Biase, Kawaguchi, \& Yamaguchi, 2015; Dyson, 2009; Eguchi \& Sugiura, 2015; Itani-Adams, 2011; Keßler, 2008; Lenzing, 2013; Pienemann, 1998; Yamaguchi, 2009, 2013; Yamaguchi \& Kawaguchi, 2014; Zhang \& Widyastuti, 2010) and most of them have shown support for the prediction of PT. However, there are still some issues to be addressed regarding the hypothesized PT stages for the English plural morpheme - $s$. In Charters, Jansen, and Dao's (2011) crosssectional study on 36 Vietnamese learners of English, aged 13 to 18, Vietnamese learners were found to have acquired the English plural $-s$ on nouns with numeral quantifiers, as in two cats before the plural $-s$ on nouns without quantifiers. Charters, et al (2011) argue that Vietnamese learners tend to acquire the phrasal plural $-s$ with numeral quantifiers earlier since classifiers are used to express plurality instead of grammatical morphemes in the Vietnamese language.

In contrast, Yamaguchi and Kawaguchi (2014), based on the data from Yamaguchi's (2009, 2013) two-year longitudinal study of a Japanese child, aged 5 to 7, learning English in a naturalistic environment, demonstrated that the plural morpheme $-s$ was acquired in the following order: plural $-s$ without quantifiers, as in cats $>$ plural $-s$ with numeral quantifiers, as in two cats $>$ plural $-s$ with other quantifiers, as in many cats. That is, the lexical plural $-s$ was found to develop earlier than the phrasal plural $-s$ in English as a second language (ESL) acquisition by the Japanese child, although the Japanese language also uses classifiers to express plurality instead of grammatical morphemes as does the Vietnamese language. However, since Yamaguchi and Kawaguchi (2014) examined only one Japanese L1 child, more studies on a larger number of learners are clearly needed to address the issue of whether the prediction of PT can be applicable to the acquisition of English plural marking by learners whose first languages are "classifier languages".

Another issue which needs to be addressed concerning PT is that the hypothesized stages of L2 development have been tested mainly with spoken data in previous studies. Tang and Zhang (2015) was the first to compare PT stages in their cross-sectional study of six Chinese university students learning in English as a foreign language (EFL) environments using both spoken and written tasks. They found that learners produced more English words in writing than in speaking. 
Also, they showed that five learners performed better in writing, and only one learner was at the same stage for speaking and writing. Since they examined only six learners, learners' speaking and writing stages need to be examined based on larger learner corpora.

\section{Study}

\subsection{Research questions and hypotheses}

In order to fill the gaps in ESL/EFL research and PT-based studies, the present study attempts to construct a learner corpus of Japanese EFL learners and to investigate the use of the plural morpheme $-s$ according to the linguistic contexts of their spoken and written performances. The following research questions are formulated:

1. Is the developmental sequence of the lexical plural $-s$ and phrasal plural $-s$ found in Japanese EFL learners' production compatible with the prediction in PT?

2. Do Japanese EFL learners use the plural morpheme $-s$ differently in spoken and written tasks?

As to the first question, we hypothesize that Japanese EFL learners acquire the lexical plural $-s$ earlier than the phrasal plural $-s$ as hypothesized in PT. Although Charters, et al (2011) have claimed that the phrasal $-s$ in numeral contexts emerges earlier than the lexical plural $-s$, PT argues that the information exchange between the two constituents (the head noun and the numeral quantifier in this case) requires higher a procedural skill, namely phrasal procedure.

Regarding the second question, Pienemann (1998) has shown that the developmental status of the learners' grammar does not vary according to different elicitation tasks based on the results from studies on ESL learners in six different tasks. Although he examined only speech production of ESL learners, we hypothesize that Japanese EFL learners use the plural morpheme $-s$ in similar ways in both spoken and written tasks.

\subsection{The participants}

291 Japanese learners of English, aged 18 to $23(\mathrm{M}=19.16, \mathrm{SD}=.906)$, participated in this study. All of them were enrolled in English language courses in Japanese universities when the data collection was conducted and most of them started studying English as a school subject after they entered junior high school at the age of 12 to 13 . In other words, the participants in this study were learning English in foreign language environments. As a control group, data was also collected from 8 native speakers of English around the same age (i.e., aged 20 to 26, $\mathrm{M}=21.88, \mathrm{SD}=1.808$ ).

\subsection{Data collection}

A wordless picture book called Frog, where are you? (Mayer, 1969) was used to elicit learners' spoken and written narratives. The picture book consists of 24 pictures without words and each of the participants was asked to perform two tasks, namely spoken and written narratives, after looking through all the pictures. To minimize ordering effects, half of the participants were asked to start with spoken narratives and half to start with written narratives. Written narratives were recorded with pen and paper by the participants, and spoken narratives were audio-recorded and transcribed.

\subsection{Learner corpus construction}

A learner corpus containing spoken and written narratives performed by Japanese learners (i.e., 291 spoken and 291 written narratives) was constructed. One file contains meta data such as the type of task (spoken/written) and the learners' narratives page by page of the picture book. A corpus of spoken and written narratives performed by 8 native speakers was also constructed in the same way to serve as control group data.

\subsection{Data analysis}

Type/Token Ratio (TTR) in speaking and writing by the Japanese learners and native speakers of English was examined using WordSmith Tools, version 6 (Scott, 2012). The frequency of the plural $-s$ on nouns (i.e., lexica plural $-s$, phrasal plural $-s$ with numeral quantifiers, phrasal plural $-s$ with non-numerical quantifiers, and over-supply of lexical plural $-s$ ) was also analysed for both the Japanese learners and the native speakers of English. Moreover, statistical analysis was conducted to examine whether there was a significant correlation between speaking and writing among the participants.

The participants' use of English grammatical morphemes was analyzed based on PT. While most of the previous studies examined the development of morphology based on accuracy, PT has applied the emergence criterion. According to PT, "emergence can be understood as the point in time at which certain skills have, in principle, been attained or at which certain operation can, in principle, be carried out" (Pienemann, 1998:138). PT claims that using a grammatical structure at a high level of accuracy, even $80 \%$ to $90 \%$, does not guarantee that the learner will be able to continue producing that structure at the same or higher level of accuracy in the future. Hence, the first productive use is regarded as the start of acquisition of the grammatical structure, namely the plural morpheme $-s$, in this study following the acquisition criterion in PT.

Regarding the lexical plural $-s$, this study analyzes whether the plural $-s$ appeared in plural contexts at least once, and then examines whether the plural $-s$ was supplied on nouns with lexical variation or morphological variation. A structure is usually considered to have been acquired when it is supplied with both lexical and morphological variation. However, this study uses only narrative tasks, so the plural $-s$ is determined to have been acquired when it was supplied in the obligatory context either with lexical variation as in (1) and (2) or with morphological variation as in (3) and (4). Learners who can produce the lexical plural $-s$, can be at stage 2 . 
Lexical variation:

(1) There are beautiful flowers.

(2) The boy found frogs.

Morphological variation:

(3) The boy found frogs.

(4) His frog is in the jar.

As for the phrasal plural $-s$ with quantifiers, we first examined whether the plural $-s$ on nouns occurred with numeral quantifiers (i.e., two, and four) or non-numeral quantifiers (i.e., many, and some) and then checked the lexical and morphological variation of its use. In this study, the phrasal $-s$ on nouns with quantifiers was determined to have been acquired when it appeared either with lexical variation as in (5) and (6) or with morphological variation as in (7) and (8). Learners, who can produce the phrasal plural $-s$ with quantifiers, can be at stage 3 .

Lexical variation:

(5) The boy found some frogs.

(6) There are many frogs.

Morphological variation:

(7) There are many frogs.

(8) The frog is in the jar.

\section{Results and Discussion}

4.1 Token, type, type/token ratio (TTR)

Tables 2 and 3 summarizes the number of Token, Type, Type/Token Ratio (TTR) found in spoken and written narratives performed by Japanese learners and native speakers of English.

Table 2. Token, type, type/token ratio performed by Japanese learners

\begin{tabular}{llll}
\hline & Speaking & Writing & Correlation \\
\hline Number of files & 291 & 291 & - \\
\hline Token & $M=318.13$ & $M=301.51$ & $.797^{* *}$ \\
\hline Type & $M=93.00$ & $M=102.89$ & $.825^{* *}$ \\
\hline Type Token Ratio & $M=30.63$ & $M=35.08$ & $.682^{* *}$ \\
\hline
\end{tabular}

Table 3. Token, type, type/token ratio performed by native speakers of English

\begin{tabular}{llll}
\hline & Speaking & Writing & Correlation \\
\hline Number of files & 8 & 8 & - \\
\hline Token & $M=449.12$ & $M=385.87$ & $.966^{* *}$ \\
\hline Type & $M=154.88$ & $M=158.88$ & $.938^{* *}$ \\
\hline Type Token Ratio & $M=35.96$ & $M=42.81$ & $.934^{* *}$ \\
\hline
\end{tabular}

Note. * : Correlation is significant at the 0.01 level (2-tailed).

According to the above tables, both Japanese learners and native speakers of English produced more English words in speaking than in writing. However, as seen in the type, and the type token ratio, they produced more different types of words in writing than in speaking. In addition, native speakers of English produced more English words in both speaking and writing than Japanese learners, as expected.

4.2 Output frequency of the plural $-s$ on nouns

Tables 4 and 5 summarize the output frequency of the plural $-s$ on nouns which appeared in spoken and written narratives performed by Japanese learners and native speakers of English.

Table 4. Output frequency of the plural $-s$ by Japanese learners

\begin{tabular}{llll}
\hline & Speaking & Writing & Correlation \\
\hline Lexical plural $-s$ (without quantifiers) & $721(M=2.48)$ & $632(M=2.17)$ & $.502^{* *}$ \\
\hline Phrasal plural $-s$ with numeral quantifiers & $148(M=.51)$ & $158(M=.54)$ & $.627^{* *}$ \\
\hline Phrasal plural $-s$ with other quantifiers & $216(M=.74)$ & $217(M=.75)$ & $.629^{* *}$ \\
\hline Over-supply of lexical plural $-s$ & $828(M=2.85)$ & $26(M=.09)$ & $.276^{* *}$ \\
\hline
\end{tabular}




\begin{tabular}{|c|c|c|c|}
\hline & Speaking & Writing & Correlation \\
\hline Lexical plural $-s$ (without quantifiers) & $66(M=8.25)$ & $34(M=4.25)$ & $.843 * *$ \\
\hline Phrasal plural $-s$ with numeral quantifiers & $5(M=.63)$ & $5(M=.63)$ & .226 \\
\hline Phrasal plural $-s$ with other quantifiers & $7(M=.88)$ & $7(M=.88)$ & .501 \\
\hline Over-supply of lexical plural $-s$ & $3(M=.38)$ & $0(M=.00)$ & - \\
\hline
\end{tabular}

Note. * : Correlation is significant at the 0.01 level (2-tailed).

Both Japanese learners and native speakers of English produced the lexical plural $-s$ more often in speaking than in writing, and native speakers of English produced the lexical plural $-s$ much more often in speaking. There was no significant difference in the use of the phrasal plural $-s$ between the speaking and writing tasks among either the Japanese learners or the native speakers of English. However, the Japanese learners over-supplied the lexical plural $-s$ much more often in speaking than in writing. In addition, the native speakers of English produced the plural $-s$ more overall, especially the lexical plural $-s$, compared with the Japanese leaners, as expected.

\subsection{Acquisition of the plural morpheme $-s$ on nouns}

Table 6 summarizes the acquisition of the plural morphemes $-s$ on nouns found in the spoken and written narratives performed by the Japanese learners. The first two rows show structures examined in this study, including the lexical plural $-s$, the phrasal plural $-s$ with numeral quantifiers, and the phrasal plural $-s$ non-numeral quantifiers. A “+” indicates that the plural $-s$ can be determined to have been acquired based on PT criterion. A " $(+)$ " was entered when the plural -s emerged but did not appear sufficiently to meet PT criterion. A "-" was entered when the learners failed to supply the plural $-s$ on nouns in plural contexts. A " " was entered when there was no plural context. In total, 46 different patterns for the acquisition of the plural $-s$ were identified and the number of learners identified for each pattern in each task were counted. The patterns were also classified into PT stages based on the acquisition criterion in PT and the number of learners found for each stage was counted. The mark "?" indicates that the plural $-s$ did not appear sufficiently to analyze the learners' stage based on PT. The acquisition patterns showing the revised developmental order of the lexical plural $-s$ and the phrasal plural $-s$ are indicated with "reversed".

In Table 6, Patterns 1 to 8 can be regarded as stage 3 since both the lexical and phrasal plural $-s$ were acquired by the learners. Thus, 109 learners were found to be at stage 3 in speaking and 113 learners in writing. Patterns 9 to 15 can be regarded as stage 2 since the learners did not produce the phrasal plural $-s$ sufficiently or at all while the lexical plural $-s$ appeared sufficiently. Hence, 78 learners were found to be at stage 2 in speaking and 72 learners in writing. Pattern 16 can be regarded as stage 1 since the learner failed to produce both the lexical or phrasal plural $-s$ successfully. Only one learner was found to be at stage 1 in both speaking and writing. Overall, the data from 188 learners (i.e., 64.6\%) in speaking and 186 learners (i.e., 63.9\%) in writing has shown support for the developmental sequence of the lexical plural $-s$ and the phrasal plural $-s$.

As for patterns 17 to 27 , the lexical plural $-s$ emerged but did not appear sufficiently, so it is difficult to determine the learners' stage based on PT even where the phrasal plural $-s$ occurred sufficiently. Regarding patterns 28 to 37, there was no context for the lexical plural $-s$. Hence, the learners' stage cannot be determined even where the phrasal plural $-s$ was produced sufficiently. Although the learners failed to produce the lexical plural $-s$ in patterns 38 to 40 , there was no context for either the phrasal plural $-s$ with numeral quantifiers or that with non-numeral quantifiers. Thus, it is difficult to determine whether the learners are at stage 1 . Thus, the data from 90 learners in speaking and 97 learners in writing who indicated patterns 17 to 40 were excluded from the analysis for PT stages because of insufficient evidence.

Patterns 41 to 46 show the reversed developmental orders where the learners acquired the phrasal plural $s$ but failed to produce the lexical plural $-s$. In other words, the development of the lexical and the phrasal plural $-s$ found in the speaking tasks of 13 learners and the writing tasks of 8 learners was inconsistent with the prediction in PT. However, the data from only $4.5 \%$ of the speaking tasks and $2.7 \%$ of the writing tasks shows evidence against PT. Therefore, it can be argued that this study has demonstrated support for the developmental sequence of the lexical and plural $-s$ as predicted in PT.

Charters, et al. (2011)'s findings indicated that learners whose first languages are classifier languages tend to acquire the plural $-s$ with numerical quantifiers earlier than the lexical plural $-s$ (without quantifiers). This is the pattern indicated by rows 42,44 , and 46 of Table 6 , as identified in this study. However, since the data from only 7 learners (i.e., 2.4\%) in both speaking and writing followed the pattern of reversed order, it can be argued that the results in this present study do not support the finding of Charters, et al. (2011).

Statistical analysis shows that there is a strong agreement in the acquisition of plural $-s$ on nouns between the Japanese learners' speaking and writing, and this correlation is statistically significant at the 0.01 level.

As for native speakers of English as a control group, the lexical plural $-s$ was produced sufficiently by all the speakers in both speaking and writing, and nobody failed to supply the plural $-s$ on nouns when they used quantifiers. However, they did not use quantifiers frequently in their narratives. In particular, two of them in speaking and one of them in 
writing never used numeral or non-numeral quantifiers. This suggests that more finely-tuned tasks may be needed to elicit the use of quantifiers in both speaking and writing.

Table 6. Acquisition of the plural morpheme $-s$ by Japanese learners

\begin{tabular}{|c|c|c|c|c|c|c|c|c|}
\hline \multirow[b]{2}{*}{$\begin{array}{c}\text { Acquisition } \\
\text { Pattern }\end{array}$} & \multirow[b]{2}{*}{$\begin{array}{c}\text { Lexical } \\
\text { plural - } \\
\quad s\end{array}$} & \multicolumn{2}{|c|}{ Phrasal plural $-s$} & \multicolumn{2}{|c|}{ Number of learners } & \multirow[b]{2}{*}{$\begin{array}{c}\text { PT } \\
\text { stage }\end{array}$} & \multicolumn{2}{|c|}{ Number of learners } \\
\hline & & $\begin{array}{c}\text { with } \\
\text { numeral } \\
\text { quantifier }\end{array}$ & $\begin{array}{c}\text { with non- } \\
\text { numeral } \\
\text { quantifier }\end{array}$ & $\begin{array}{l}\text { Speaking } \\
(n=291)\end{array}$ & $\begin{array}{l}\text { Writing } \\
(n=291)\end{array}$ & & $\begin{array}{l}\text { Speaking } \\
(\mathrm{n}=291)\end{array}$ & $\begin{array}{c}\text { Writing } \\
(\mathrm{n}=291)\end{array}$ \\
\hline 1 & + & + & + & 37 & 37 & \multirow{8}{*}{3} & \multirow{8}{*}{109} & \multirow{8}{*}{113} \\
\hline 2 & + & + & $(+)$ & 6 & 5 & & & \\
\hline 3 & + & $(+)$ & + & 1 & 1 & & & \\
\hline 4 & + & $(+)$ & $(+)$ & 0 & 1 & & & \\
\hline 5 & + & + & l & 23 & 27 & & & \\
\hline 6 & + & l & + & 30 & 33 & & & \\
\hline 7 & + & + & - & 2 & 7 & & & \\
\hline 8 & + & - & + & 5 & 3 & & & \\
\hline 9 & + & $(+)$ & - & 0 & 1 & \multirow{7}{*}{2} & \multirow{7}{*}{78} & \multirow{7}{*}{72} \\
\hline 10 & + & I & $(+)$ & 6 & 11 & & & \\
\hline 11 & + & - & $(+)$ & 0 & 1 & & & \\
\hline 12 & + & / & 1 & 50 & 39 & & & \\
\hline 13 & + & 1 & - & 12 & 14 & & & \\
\hline 14 & + & - & - & 7 & 3 & & & \\
\hline 15 & + & - & - & 3 & 3 & & & \\
\hline 16 & - & - & - & 1 & 1 & 1 & 1 & 1 \\
\hline 17 & $(+)$ & + & + & 2 & 6 & \multirow{24}{*}{$?$} & \multirow{24}{*}{90} & \multirow{24}{*}{97} \\
\hline 18 & $(+)$ & + & $(+)$ & 1 & 5 & & & \\
\hline 19 & $(+)$ & $(+)$ & + & 2 & 0 & & & \\
\hline 20 & $(+)$ & + & I & 7 & 7 & & & \\
\hline 21 & $(+)$ & + & - & 0 & 2 & & & \\
\hline 22 & $(+)$ & 1 & + & 6 & 3 & & & \\
\hline 23 & $(+)$ & 1 & $(+)$ & 3 & 4 & & & \\
\hline 24 & $(+)$ & I & 1 & 17 & 9 & & & \\
\hline 25 & $(+)$ & I & - & 1 & 6 & & & \\
\hline 26 & $(+)$ & - & I & 5 & 3 & & & \\
\hline 27 & $(+)$ & - & - & 3 & 1 & & & \\
\hline 28 & I & + & + & 4 & 4 & & & \\
\hline 29 & I & + & $(+)$ & 1 & 1 & & & \\
\hline 30 & 1 & + & 1 & 1 & 3 & & & \\
\hline 31 & I & I & + & 5 & 6 & & & \\
\hline 32 & I & - & + & 2 & 1 & & & \\
\hline 33 & I & I & $(+)$ & 1 & 1 & & & \\
\hline 34 & I & - & - & 1 & 0 & & & \\
\hline 35 & 1 & I & 1 & 6 & 6 & & & \\
\hline 36 & I & I & - & 1 & 5 & & & \\
\hline 37 & I & - & I & 0 & 1 & & & \\
\hline 38 & - & - & I & 2 & 1 & & & \\
\hline 39 & - & I & - & 8 & 9 & & & \\
\hline 40 & - & 1 & 1 & 11 & 10 & & & \\
\hline 41 & - & - & + & 2 & 0 & \multirow{6}{*}{ reversed } & \multirow{6}{*}{13} & \multirow{6}{*}{8} \\
\hline 42 & - & + & I & 5 & 5 & & & \\
\hline 43 & - & / & + & 3 & 1 & & & \\
\hline 44 & - & + & $(+)$ & 0 & 1 & & & \\
\hline 45 & - & $(+)$ & $(+)$ & 1 & 0 & & & \\
\hline 46 & - & + & + & 2 & 1 & & & \\
\hline
\end{tabular}

\subsection{Comparison of speaking and writing stages}

Table 7 shows the results of the comparison between speaking and writing stages of the Japanese learners. In the first row, " $\mathrm{S}=\mathrm{W}$ " indicates that learners were found to be at the same stages for speaking and writing. "S $>$ W" shows that the learners' speaking stages were higher than those of their writing, and vice versa for " $\mathrm{S}<\mathrm{W}$ ". Since 150 learners whose stages could not be determined based on PT were excluded, and 141 learners' stages were examined. According to the table, 108 learners (i.e., 76,6\%) were at the same stages for speaking and writing. While the number of learners 
whose speaking stages were higher than their writing stages was $13(9.2 \%)$, and the number of learners whose writing stages were higher than their speaking stages was $20(14.2 \%)$. This suggests that only a small number of learners were found to perform differently in the speaking and writing tasks examined in this study. These findings are not consistent with the results found in Tang and Zhang (2015) showing that most learners performed better in writing than in speaking and that no learners performed better in speaking than in writing. Two possible reasons for the discrepancy between these findings may be the different first languages of participants and the types of elicitation tasks. Also, while the present study focused on the use of the plural marker $-s$, Tang and Zhang (2015) analyzed verbal morphology as well.

As for native speakers, five speakers were found to be at the same stages for speaking and writing, but one speaker performed better in writing than in speaking, while two speakers performed better in writing than in speaking.

Table 7. Comparison of speaking and writing stages by Japanese learners

\begin{tabular}{cccccc}
\hline & \multicolumn{2}{c}{$\mathrm{S}=\mathrm{W}$} & $\mathrm{S}>\mathrm{W}$ & \multicolumn{2}{c}{$\mathrm{S}<\mathrm{W}$} \\
\hline Speaking stage & 3 & 2 & 3 & 2 & 1 \\
\hline Writing stage & 3 & 2 & 2 & 3 & 2 \\
\hline $\begin{array}{c}\text { Numbers of } \\
\text { learners }\end{array}$ & 73 & 35 & 13 & 19 & 1 \\
\hline $\begin{array}{c}\mathrm{n}=141 \\
(=291-150)\end{array}$ & $108(76.6 \%)$ & $13(9.2 \%)$ & $20(14.2 \%)$ & \\
\hline
\end{tabular}

\section{Conclusion}

This study examines the spoken and written narratives performed by 291 Japanese university students learning English in foreign language environments and demonstrates that the developmental sequence of the lexical and phrasal plural $-S$ hypothesized in PT is supported by the data from 188 learners in speaking and 186 learners in writing. Although the ratio of learners who showed support for PT stages was not very high (i.e., $64.6 \%$ in speaking, $63.9 \%$ in writing), the reversed developmental order ratios were found in the narratives by only a limited number of learners (i.e., $4.5 \%$ in speaking, $2.7 \%$ in writing). Also, the data from only 7 learners $(2.4 \%)$ was consistent with the findings of Charters, et al (2011). Therefore, it can be argued that the results of this study show support for the prediction model of PT. Furthermore, it suggests that there is a connection between speaking and writing among Japanese learners, while only a small number of learners are shown to perform differently in speaking and writing tasks; however, this finding is not consistent with the results of Tang and Zhang (2015). Since this study focuses on the use of the plural morpheme $-s$ in spoken and written narratives by Japanese learners, more research is needed to test PT stages in other grammatical structures, such as other morphological and syntactic structures, and to investigate differences between learners' speaking and writing production.

\section{Acknowledgements}

This project is in part supported by JSPS KAKENHI Grant (15K02762). We would like to thank the participants of the 16th International Symposium of Processability Approaches to Language Acquisition (PALA 2016) held in Chuo University, Japan on 7-8 September 2016 and the anonymous reviewers for their valuable comments on the early versions of this paper. We are also grateful to Kikuko Nakamura, Satomi Kawaguchi, and Bruno Di Biase for their kind assistance with data collection and analysis. Further, our gratitude goes to Simeon Flowers for his proofreading.

\section{References}

Charters, H., Dao, L., \& Jansen, L. (2011). Reassessing the applicability of Processability Theory: The case of nominal plural. Second Language Research, 27 (4), 509-533.

Di Biase, Kawaguchi, \& Yamaguchi (2015). The development of English as a second language. In C. Bettoni \& B. Di Biase (Eds.), Grammatical development in second languages: Exploring the boundaries of Processability Theory (pp. 85-115). European Second Language Association.

Dyson, B. (2009). Processability Theory and the role of morphology in English as a second language development: a longitudinal study. Second Language Research, 25 (3), 355-376.

Eguchi, A., \& Sugiura, M. (2015). Applicability of processability theory to Japanese adolescent EFL learners: A case study of early L2 syntactic and morphological development. System, 52, 115-126.

Itani-Adams, Y. (2011). Bilingual first language acquisition. In M. Pienemann \& J.-U. Keßler (Eds.), Studying processability theory (pp. 121-130). Amsterdam: John Benjamins. 
Keßler, J.-U. (Ed.) (2008). Processability approaches to second language development and second language learning. Newcastle: Cambridge Scholars Press.

Lenzing, A. (2013). The Development of the grammatical system in early second language acquisition: The Multiple Constraints Hypothesis. Amsterdam: John Benjamins.

Levelt, W. J. M. (1989). Speaking. Cambridge, Massachusetts: The MIT Press.

Mayer, M. (1969). Frog, where are you? New American Library.

Pienemann, M. (1998). Language processing and second language development: Processability Theory. Amsterdam: John Benjamins.

Pienemann, M. (Ed.) (2005). Cross-linguistic aspects of Processability Theory. Amsterdam: John Benjamins.

Scott, M. (2012). WordSmith tools version 6. Stroud: Lexical Analysis Software.

Tang, H. \& Zhang, Y. (2015). An investigation of Chinese students' acquisition of oral and written English through the measurement of Processability Theory. International Journal of Applied Linguistics \& English Literature, 4 (2), 207212.

Yamaguchi, Y. (2009). The development of plural marking and plural agreement in child English L2 acquisition. In J.-U. Keßler, and D. Keatinge (Eds.), Research in second language acquisition: Empirical evidence across languages (pp. 939). Newcastle upon Tyne, UK: Cambridge Scholars Publishing.

Yamaguchi, Y. (2013). Child second language learning: A study of English as a second language acquisition. Saarbrücken, Germany: LAP Lambert Academic Publishing.

Yamaguchi, Y. \& Kawaguchi, S. (2014). Acquisition of English morphology by a Japanese school-aged child: A longitudinal study. The Asian EFL Journal Quarterly, 16(1), 89-119.

Yamaguchi, Y. \& Usami, H. (2016). Eigogakushusha no "hanasu chikara" "kakuchikara" no jissho kenkyuu: fukusuu wo arawasu keitaiso no bunseki. [An empirical research on speaking and writing by Japanese learners of English: An analysis of the use of plural marking morphology]. The Report of International Education Center, Tokai University, Volume 36, pp. 57-64.

Zhang, Y. \& Widyastuti, I. (2010). Acquisition of L2 English morphology: A family case study. Australian review of applied linguistics, 33 (3), 29.1-29.17. 